\title{
A Molecular Marker Identifying Subspecific Populations of the Soybean Brown Stem Rot Pathogen, Phialophora gregata
}

\author{
Weidong Chen, Craig R. Grau, Eric A. Adee, and Xiangqi Meng
}

First and fourth authors: Illinois Natural History Survey, and Department of Crop Sciences, University of Illinois at Urbana-Champaign, 607 East Peabody Drive, Champaign 61820, second author: Department of Plant Pathology, University of Wisconsin, 1607 Linden Drive, Madison 53706, third author: Department of Crop Sciences, University of Illinois at Urbana-Champaign, 1102 South Goodwin, Urbana, 61801.

Accepted for publication 27 April 2000.

\begin{abstract}
Chen, W., Grau, C. R., Adee, E. A., and Meng, X.-Q. 2000. A molecular marker identifying subspecific populations of the soybean brown stem rot pathogen, Phialophora gregata. Phytopathology 90:875-883.

A molecular marker was developed to separate and identify subspecific populations of Phialophora gregata, the causal agent of soybean brown stem rot. A variable DNA region in the intergenic spacer of the nuclear rDNA was identified. Two specific primers flanking the variable region were developed for easy identification of the genotypes using polymerase chain reaction (PCR). These two specific primers amplified three DNA products. The three PCR products were used to separate isolates of $P$. gregata into distinct genotypes: A (1,020 bp), B (830 bp), and C (660 bp). Genotype $\mathrm{C}$ was found in isolates obtained from Adzuki beans from Japan, whereas all 292 isolates obtained from

soybean and the 8 isolates from mung bean belonged to either genotype A or B. The original nondefoliating (type II) strain ATCC 11073 (type culture of $P$. gregata) belonged to genotype B. The difference between genotypes A and B was due only to an 188-bp insertion or deletion; genotype $\mathrm{C}$, however, differs from genotypes $\mathrm{A}$ and $\mathrm{B}$ at 58 point mutations, in addition to the length difference. Isolates of both genotypes A and B were widespread in seven Midwestern states. Genotype A was found mostly in certain susceptible soybean cultivars like Sturdy and Pioneer 9305, whereas genotype B was found predominately in brown stem rot-resistant soybean cvs. Bell, IA 3003, and Seiben SS282N. The specific primers were also used to directly detect cultivar-preferential infection by the two genotypes in infected soybean stems growing in the same field. Data from direct detection in soybean stems showed that cultivarpreferential infection by the two genotypes of $P$. gregata was significant.
\end{abstract}

The fungal pathogen Phialophora gregata (Allington \& D.W. Chamberlain) W. Gams causes soybean brown stem rot (BSR). The disease has been reported in the United States (3), Canada (22), Egypt (17), Japan (24), Mexico (31), and Yugoslavia (41). In the United States, it occurs mainly in the north central states $(16,29,46)$, although it also has been reported in some eastern and southern states $(12,17)$. The fungus is soilborne, infects soybean vascular tissue, and causes discoloration of the pith and vascular tissue of the stem and interveinal necrosis. The disease may cause up to $30 \%$ yield loss under conditions favorable for disease development $(1,29,36)$. Resistant cultivars and crop rotation are the only practical methods for controlling BSR. Significant progress has been made in breeding soybeans for BSR resistance and in understanding the soybean genetics of BSR resistance $(9,26,33,44)$ and the effect of cultural practices on development of the disease $(2,19,29,36)$. However, limited information is available on the genetics of the pathogen, particularly on the genetic structure of $P$. gregata that infects soybean.

Isolation and identification of the pathogen is problematic due to the presence of other morphologically similar fungi in soybean stems and the slow growth of $P$. gregata (28). The pathogen can be differentiated from other fungi associated with soybean stems based on isozyme banding patterns (28), DNA sequences of internal transcribed spacer (ITS) regions of rDNA $(10,12,20)$, and total cellular DNA content determined with a flow cytometer (15). Based on ITS sequences, Chen et al. $(10,12)$ identified one of the

Corresponding author: W. Chen; E-mail address: w-chen7@ uiuc.edu

Publication no. P-2000-0619-02R

(c) 2000 The American Phytopathological Society fungi ecologically associated with BSR, Plectosporium tabacinum, which was later confirmed by Harrington et al. (20) also using ITS sequences. Specific primers were developed for detection of $P$. gregata in infected stems of resistant and susceptible soybean cultivars (10).

Variation in virulence among $P$. gregata isolates has been reported. Gray (16) reported two pathogenicity types of isolates in $P$. gregata, which were also observed in other independent studies $(28,45)$. Defoliating (type I) isolates caused vascular discoloration and wilting symptoms, whereas nondefoliating (type II) isolates, which include the type culture of $P$. gregata, cause only vascular discoloration in stems (16). A high level of variability in virulence was found using a set of four differential soybean cultivars (45). Mengistu and Grau (28) found a wide range of pathogenicity among 24 isolates of $P$. gregata on a susceptible soybean cultivar. Isolates of $P$. gregata obtained from the same field also exhibited variation in pathogenicity against soybean genotypes (36).

Isolates of $P$. gregata from soybean and Adzuki bean have different pathogenicity spectra and are recognized as different formae specialis (24). Genetic differences between the formae speciales are well documented $(10,11,18,47,48)$. However, isolates from soybean appear monomorphic based on isozyme banding patterns (28), restriction banding patterns of mitochondrial DNA (18), and ITS sequences of rDNA (10).

rDNA repeat units have coding and noncoding spacer regions that evolve at different rates (7). The spacer regions evolve rapidly and are useful in studying closely related taxa. The ITS region is useful for taxonomic studies at the species level (13). The intergenic spacer region (IGS) between rDNA transcription units is more variable and has been used to discriminate subspecific populations of plant-pathogenic fungi $(5,6,32,38,39)$. Henrion et al. (21) found that the IGS region was variable within species of truffles. 
The IGS region was also used to differentiate strains in clinically important fungi $(23,34)$.

This study was aimed at discovering genetic structure within $P$. gregata isolated from soybean by exploring the variation in the IGS region of nuclear rDNA. We found that the IGS region can be used to subdivide $P$. gregata into distinct genotypes and that the genotypes of $P$. gregata preferentially infect certain soybean cultivars under field conditions.

\section{MATERIALS AND METHODS}

Fungal strains and DNA isolation. Strains of $P$. gregata were isolated from infected soybean plants with a semiselective medium (30) or water agar (16 g of agar per liter of water) amended with $100 \mathrm{ppm}$ of streptomycin. Each isolate was obtained from a different plant. Isolates of $P$. gregata were collected from seven states in the United States and from Brazil, Canada, and Japan (Table 1). Strains were further purified either from the hyphal tip or by isolation of single conidia. Strains were grown in green bean agar ( $25 \mathrm{~g}$ of frozen green beans blended and filtered through four layers of cheesecloth with $15 \mathrm{~g}$ of agar per 1 liter) for 2 weeks. Agar plugs containing mycelium and conidia were stored in sterile water at $4^{\circ} \mathrm{C}$.

Strains were grown in green bean broth for 2 weeks, and the mycelium was harvested by filtration. The harvested mycelium was used either immediately in DNA isolations or frozen at $-80^{\circ} \mathrm{C}$ until used. The mycelium was ground, using a mortar and pestle, to a fine powder in liquid nitrogen, and DNA was isolated from

TABLE 1. Geographic distribution of isolates of Phialophora gregata used in this study

\begin{tabular}{llccr}
\hline & & \multicolumn{2}{c}{ Number of isolates of P. gregata } \\
\cline { 2 - 5 } State/Country & Location & Genotype A & Genotype B & Total \\
\hline Illinois & Belvidere & 8 & 6 & 14 \\
& DeKalb & 6 & 0 & 6 \\
& Monmouth & 52 & 71 & 123 \\
& Urbana & 7 & 2 & 9 \\
Indiana & Unknown & 4 & 0 & 4 \\
Iowa & Unknown & 8 & 2 & 10 \\
Michigan & Unknown & 7 & 2 & 9 \\
Minnesota & Unknown & 3 & 2 & 5 \\
Ohio & Unknown & 3 & 3 & 6 \\
Wisconsin & Unknown & 2 & 1 & 3 \\
& Arlington & $20^{\mathrm{a}}$ & 15 & 35 \\
& Dairyland & 2 & 0 & 2 \\
& Hancock & 30 & 16 & 46 \\
& Lancaster & 1 & 0 & 1 \\
& Janesville & 1 & 0 & 1 \\
& West & 2 & 0 & 2 \\
Total & Madison & & & \\
Japan & Unknown & $15^{\mathrm{a}}$ & 2 & 17 \\
Canada (Ontario) & Unknown & 3 & 0 & 3 \\
Unknown & 4 & 0 & 4 \\
& Unknown & $\ldots$ & 122 & 302 \\
\hline
\end{tabular}

a Includes one genotype A' isolate.

${ }^{\mathrm{b}}$ Two genotype $\mathrm{C}$ isolates were obtained from Adzuki beans, all other isolates were from either soybean (292 isolates) or mung bean (8 isolates). the mycelium powder as previously described (10). DNA was also isolated from mycelium grown in potato dextrose agar using the FastDNA kit (Bio 101, Vista, CA) following the manufacturer's instructions.

Polymerase chain reaction and DNA cloning. Polymerase chain reaction (PCR) primers $28 \mathrm{SF}$ and CNS1R, based on the conserved $28 \mathrm{~S}$ and $18 \mathrm{~S}$ coding regions, were used to amplify the IGS region between transcription units of rDNA (Fig. 1) in four soybean isolates: H96-5, $\mathrm{Pg} 11, \mathrm{Pg} 13$, and $\mathrm{Pg} 19$ of P. gregata. Primers 28SF (5'CTG AAC GCC TCT AAG TCA GAA3') and CNS1R (5'GAG ACA AGC ATA TGA CTA C3') were the reverse complements of primers LR12 (42) and NS1 (43), respectively. PCR reactions consisted of $0.3 \mu \mathrm{M}$ of each primer, 10 to $50 \mathrm{ng}$ of DNA, $200 \mu \mathrm{M}$ dNTPs, $2 \mathrm{mM} \mathrm{MgSO} 4$ and 2.5 units of Platinum Taq DNA polymerase high fidelity (GIBCO BRL, Rockville, MD) in $1 \times$ PCR buffer in a total volume of $50 \mu \mathrm{l}$. All PCR reactions were set up using pipette tips with aerosol barriers to prevent contamination. Temperature cycles were $94^{\circ} \mathrm{C}$ for $75 \mathrm{~s}, 55^{\circ} \mathrm{C}$ for $30 \mathrm{~s}$, and $70^{\circ} \mathrm{C}$ for $6 \mathrm{~min}$ for the first cycle, followed by 40 cycles of $94^{\circ} \mathrm{C}$ for $30 \mathrm{~s}, 55^{\circ} \mathrm{C}$ for $30 \mathrm{~s}$, and $70^{\circ} \mathrm{C}$ for $6 \mathrm{~min}$. The temperature was then reduced to and kept at $4^{\circ} \mathrm{C}$. The efficacy of the PCR was monitored by running $5 \mu \mathrm{l}$ of the PCR product through $1 \%$ agarose gel electrophoresis.

Restriction enzyme digestion was used to detect variation in the PCR amplified IGS region. Eight six-base recognition enzymes, AccI, BamHI, HincII, HindIII, EcoRI, EcoRV, NcoI and SstI

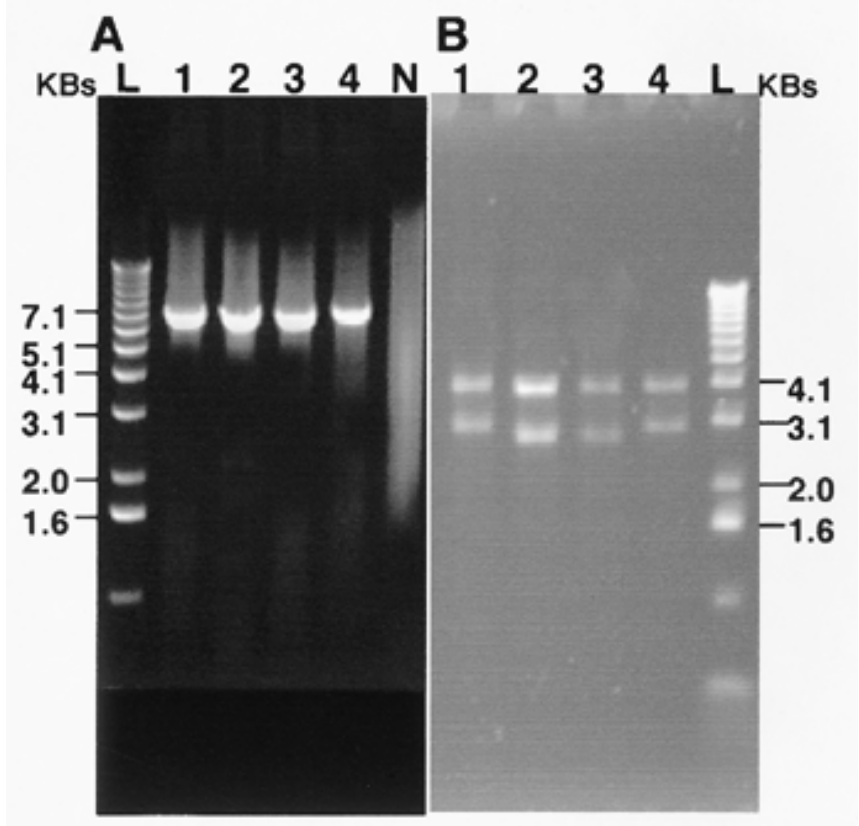

Fig. 2. Agarose gels showing A, polymerase chain reaction amplification of the intergenic spacer region (IGS) of Phialophora gregata using primers 28SF and CNS1R, and B, HindIII restriction enzyme digestion of the amplified IGS region. Lane L, BRL 1-kb DNA ladder with approximate DNA sizes indicated; lanes 1 to 4, isolates H96-5, Pg11, Pg13, and $\operatorname{Pg} 19$, respectively; lane $\mathrm{N}$, negative control without DNA template.

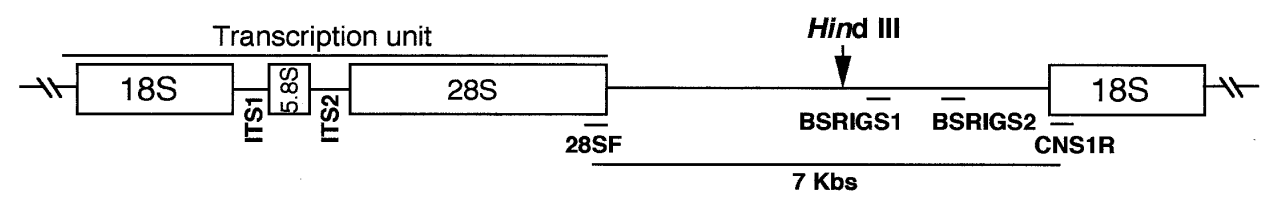

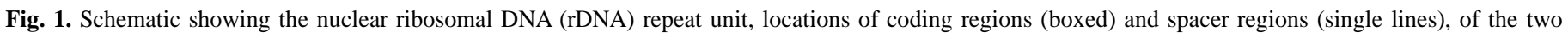

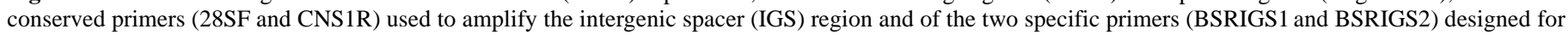

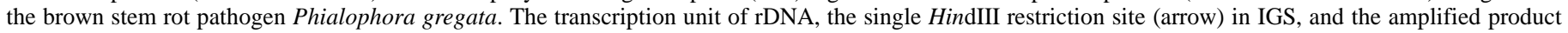
size of the IGS region are indicated. 
(GIBCO BRL) were used according to the manufacturer's instructions. Restriction fragments were separated by agarose (1\%) gel electrophoresis and photographed under ultraviolet light after staining with ethidium bromide.

To facilitate cloning PCR products, an EcoRI site was added to the $5^{\prime}$ end of both PCR primers, resulting in E28SF (5'GCG AAT TCC TGA ACG CCT CTA AGT CAG AA3') and ECNS1R (5'GCG AAT TCG AGA CAA GCA TAT GAC TAC3'). The EcoRI site was chosen because the enzyme EcoRI does not have a restriction site in the amplified IGS region (discussed below). The two primers were used in PCR as described above. The resulting PCR products were digested with restriction enzyme HindIII which is known to cut once in the amplified IGS region (Fig. 2B) and with EcoRI to cut the added restriction site in the PCR primers. This digestion process resulted in two DNA fragments, each with an EcoRI and a HindIII cohesive end, so that only one direction of insertion is possible during cloning. The two restriction fragments from each PCR product were separated by agarose gel electrophoresis. Bands were excised from the gel, purified with GeneClean (BIO 101, Inc., Vista, CA), and ligated into the EcoRI and HindIII sites of pGEM $3 \mathrm{ZF}(+)$ plasmid vector (Promega Corporation, Madison, WI). The resulting recombinant plasmids were used to transform Escherichia coli strain JM 109 high competent cells prepared according to standard protocols (35). Recombinant colonies were identified by color selection after overnight growth at $37^{\circ} \mathrm{C}$ on Luria-Bertani agar plates containing ampicillin at $150 \mu \mathrm{g} / \mathrm{ml}$ and X-gal (5-bromo-4-chloro3 -indolyl $\beta$-D-galactoside) at $27 \mu \mathrm{g} / \mathrm{ml}$ and IPTG (isopropyl-thio$\beta$-D-galactoside) at $27 \mu \mathrm{g} / \mathrm{ml}$. Two to eleven white colonies from each insert were selected, and plasmid DNAs were isolated from each clone with the Wizard Plus SV Miniprep kit (Promega). After confirming the fragment size of the insert by digestion with enzymes EcoRI and HindIII and electrophoresis, the plasmid DNAs from each DNA insert of a given isolate were combined before sequencing.

DNA sequencing and specific PCR primers. A primer walking strategy was used to sequence the cloned DNA fragments. The two promoter sequences (T7 and SP6) located near each end of the insert on the vector were first used in cycle sequencing with fluorescent dye terminators in either the Thermal Sequenase kit (Amersham Life Sciences, Cleveland, $\mathrm{OH}$ ) or the

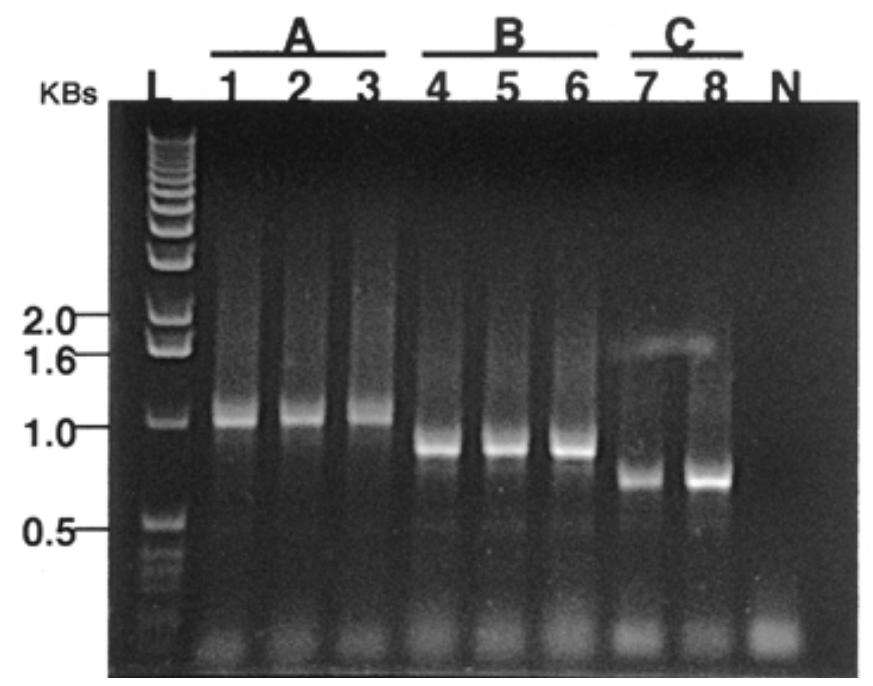

Fig. 3. Agarose gel showing polymerase chain reaction (PCR) amplification using specific primers BSRIGS1 and BSRIGS2. The three PCR product sizes of $\approx 1,020,830$ and 660 bp were designated as genotypes A, B, and C, respectively. Lane L, BRL 1-kb DNA ladder with approximate DNA sizes indicated; lanes 1 to 3, isolates 98A1-1-2, 98A2-3, and 98B4-6 of genotype A, respectively; lanes 4 to 6 , isolates 98A5-3, 98A5-4, and 98A5-5 of genotype B, respectively; lanes 7 and 8, isolates ATCC 46906 and 5-22 of genotype $\mathrm{C}$, respectively; lane $\mathrm{N}$, negative control without DNA template.
ABI Prism BigDye Terminator Cycle Sequencing kit (PerkinElmer Applied Biosystems, Foster City, CA). DNA sequences were determined with the ABI 377 automated DNA sequencer at the Biotechnology Center of the University of Illinois, UrbanaChampaign. During the design of additional sequencing primers, DNA sequences of the same sequencing primer from all four isolates were compared using the program Sequencher (Gene Codes Corporation, Ann Arbor, MI) to ensure that the new primers would work for all four isolates.

The Sequencher program was also used to determine the DNA region that was variable among the four isolates. Two specific primers were designed to flank the variable region. The two primers were BSRIGS1 (5'GGG GTT CCG GGA TTC ACA GG3') and BSRIGS2 (5'GAG TGG TAA ATG GGG TAA TCA AC3'). The composition of PCR reactions was the same as those described above except that regular Taq DNA polymerase (GIBCO BRL) and a total volume of $10 \mu \mathrm{l}$ were used. PCR conditions for these primers were $94^{\circ} \mathrm{C}$ for $3 \mathrm{~min}, 55^{\circ} \mathrm{C}$ for $1 \mathrm{~min}$, and $72^{\circ} \mathrm{C}$ for $2 \mathrm{~min}$ for the first cycle followed by 40 cycles of $94^{\circ} \mathrm{C}$ for $45 \mathrm{~s}, 55^{\circ} \mathrm{C}$ for $45 \mathrm{~s}, 72^{\circ} \mathrm{C}$ for $1 \mathrm{~min}$ with a final extension of $3 \mathrm{~min}$ at $72^{\circ} \mathrm{C}$. The two primers were tested for specificity on DNAs of $P$. gregata, a wide range of other fungi, and soybean plants. DNA from the following fungi were included in the test, Acremonium dichromosporum, A. nepalense, Cercospora sp., Gaeumannomyces graminis, Plectosporium tabacinum, Pythium ultimum, Sclerotinia sclerotiorum, Septoria sp., and Verticillium dahliae. Plectosporium tabacinum is a frequent inhabitant of soybean stem $(10,12)$. The two Acrmonium spp. were tested because they are morphologically similar to Plectsporium, and, in fact, Plectosporium tabacinum from soybean has been referred to previously as Acremonium sp. $(18,28)$. G. graminis has a Phialophora anamorph (asexual state). Cercospora sp., Pythium ultimum, S. sclerotiorum, and Septoria sp. are known soybean pathogens (37) and are likely to occur in soybean plants.

BLAST searches (4) were conducted using the amplified sequences as queries to search for the most similar sequences in

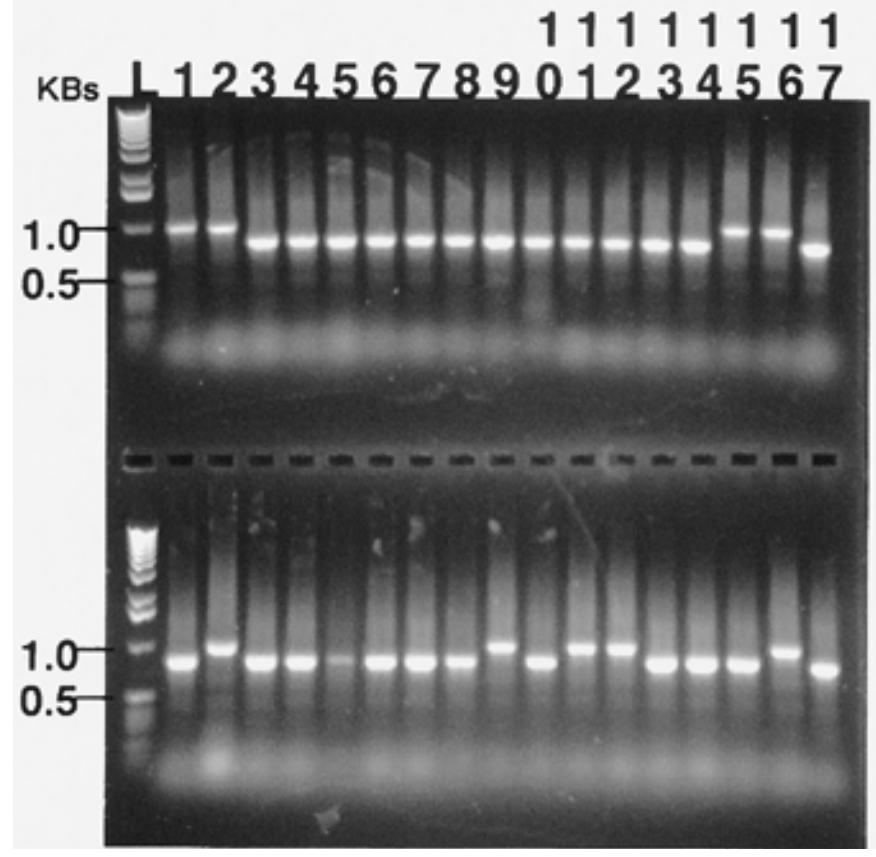

Fig. 4. Agarose gel for genotyping Phialophora gregata isolates by polymerase chain reaction amplification, using the specific primers BSRIGS1 and BSRIGS2. Lane L, BRL 1-kb DNA ladder with approximate DNA sizes indicated; lanes 1 to 17, upper panel: isolates 98A1-1-2, 98A2-3, 98A5-3, 98A5-4, 98A5-5, 98A5-6, 98B3-1, 98B3-2, 98B3-3, 98B4-1, 98B4-2, 98B43, 98B4-4, 98B4-5, 98B4-6, S1-1a, and S1-1b , respectively; lower panel: S1-2a, S1-4, S2-1, S2-2a, S2-2b, S2-3, S2-5, S3-2a, S3-2b, S3-3, S3-4, S4-1, S4-2, S4-3, S4-4, S4-5, and S5-1, respectively. 
111111111

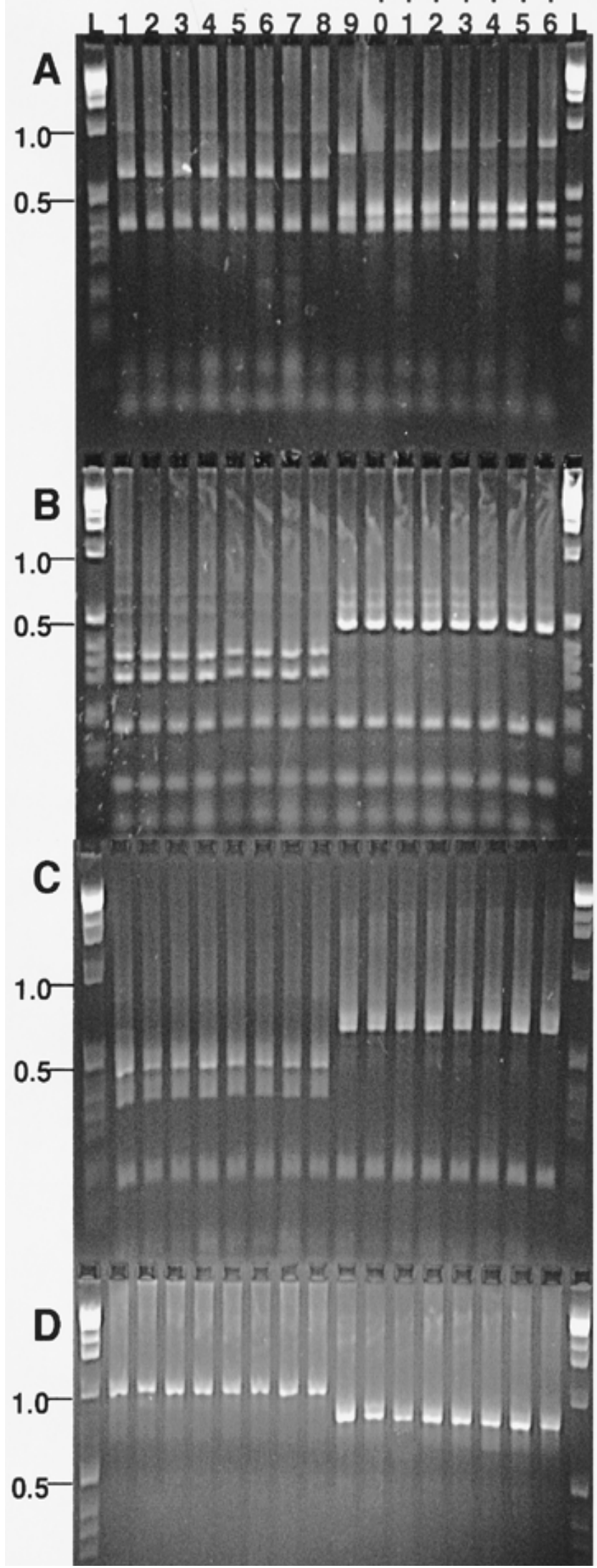

Fig. 5. Agarose (2\% NuSeive GTG and $1 \%$ regular agarose) gel showing restriction enzyme digestion of polymerase chain reaction products amplified with specific primers BSRIGS1 and BSRIGS2. Restriction digestion were carried out with enzymes of A, AccI; B, HinfI; C, BglII; or D, undigested. Lane L, BRL 1-kb DNA ladder with approximate DNA sizes (in kilobases indicated; lanes 1 to 8, isolates 98A1-1-2, 98B4-6, 98C1-5, Fulton-OH, M2, MN1, P63, and S1-4 of genotype A, respectively; lanes 9 to 16, isolates 98A4-2, 98A5-3, 98B4-1, IN4, M3, MN4, OH39, and S2-1 of genotype B, respectively.
GenBank. Sequence alignments were performed using the program Clustal W (40). Minor adjustments were made manually to the alignment outputs.

Genotype determination of isolates. The length variation in the region defined by the two specific primers was used to determine isolate genotypes. The size of the PCR product amplified with the two specific primers was determined by comparing them with DNA standards in $1 \%$ agarose gel electrophoresis. The three PCR product sizes were used to assign genotypes to isolates. Each set of PCR reactions included at least one isolate of a known genotype and a negative control without a DNA template.

To determine if there was any variation in the amplified products within each genotype, eight isolates representing various geographic origins were selected from each of the two genotypes, and the PCR products were subjected to restriction digestion with eight restriction enzymes: AccI, BglII, HinfI, MboI, MspI, RsaI, TaqI, and XbaI (GIBCO BRL). The digested fragments were separated on $3 \%$ agarose gels (1\% regular agarose and $2 \%$ NuSeive GTG agarose from FMC BioProducts, Rockland, MD) as previously described (13). In addition, the PCR products from two isolates (one from each genotype) were purified and sequenced on both strands to confirm sequence identity.

Genotype detection in infected soybean plants. The genotype data of isolates indicated that the pathogen genotypes had cultivar preferences. Therefore, this experiment was designed to verify that the cultivar preference occurred under the same field conditions. The specific primers were used to detect the presence of the pathogen and the pathogen genotype in infected soybean plants. A total of 50 plants of cvs. AP1991, Bell, BSR101, and Sturdy growing in the same field near Arlington, WI was randomly collected regardless of BSR symptoms at the end of the growing season. Plants of the same cultivars from different plots in the same field were pooled before DNA isolation. DNAs from individual soybean stems were isolated with the FastDNA kit (Bio 101) as previously described (12) and were amplified with the specific primers as described above. PCR product size was used to indicate the pathogen genotype in the particular plant. The number of plants of each cultivar that were infected by each genotype was recorded, and $\chi^{2}$ analyses were used to test the significance of the cultivar preference of the pathogen genotypes.

\section{RESULTS}

Amplification of the IGS region and DNA sequencing. PCR with primers $28 \mathrm{SF}$ and CNS1 produced a DNA band of approximately $7 \mathrm{~kb}$ in the four isolates tested (Fig. 2A). Due to its length, this IGS region can be amplified only with the high fidelity DNA polymerase. Numerous attempts with regular Taq DNA polymerase were unsuccessful. Among the eight enzymes used in digestion, four enzymes, AccI, BamHI, HindIII and NcoI, cut this DNA one to three times. The other four enzymes did not have restriction sites in this region (gel not shown). Digestion with HindIII produced two fragments of $\approx 4 \mathrm{~kb}$ (top band) and $3 \mathrm{~kb}$ (bottom band). The prominent difference among the four isolates is evident in the bottom band (Fig. 2B).

After HindIII digestion, the top and bottom bands (Fig. 2B) from each of the four isolates were cloned into a pGEM $3 \mathrm{Zf}(+)$ vector and transformed into JM 109 competent cells. When the bottom bands were used as inserts, seven clones were selected from isolate Pg13, and five clones were selected from each of the other three isolates. When the top bands were used as inserts, three clones were selected from isolate Pg13, and two clones were chosen from each of the other three isolates. The clones from each insert from the same isolate were combined before sequencing. Although both the top and bottom bands from each of the four isolates were cloned, only the clones containing the bottom bands were sequenced for this study. 
A

Type A ggggttccgggattcacagggtag-tcagatgtgagactggtgggagaggcttcagggcaccgctacaggcttctacacactgtaaggacacctagaagt

Type B ggggttccgggattcacagggtag-tcagatgtgagactggtgggagaggcttcagggcaccgctacaggcttctacacactgtagggacacctagaagt

Type $A^{\prime}$ ggggttccgggattcacagggtagctcagatgtgagactggtgggagaggcttcagggcaccgctacaggcttctacacactgtaaggacacctagaagt

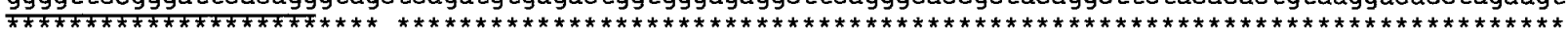

Type A cccttggcacctcccctacagcgtcggaggccctgtagccgaccctgaaggagtgccctgaggtgcgacgtgcaacaaaaccagatctgcccacgtgatt Type B cccttggcacctccctacagcgtcggaggccctgtagccgaccetgaaggagtgccetgaggtgegacgtgcaacaaaaccagatctgcccacgtgatt Type $A^{\prime}$ ccettggcacctccctacagcgtoggaggccetgtagccgaccetgaaggagtgccetgaggtgegacgtgcaacaaaccagatctgcccacgtgatt

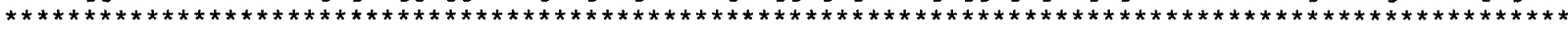

Type A ccctcagggtaggtcgagtgtggaattggtgggagaggcttcagggcactgctacaggcttgtacacactgtagggacaccctagaagtcccttggcagt Type B ccctcagggtaggtcgagtgtggaattggtgggagaggcttcagggcactgctacaggcttgtacacactgtagggacaccctagaagtccettggcagt Type $A^{\prime}$ ccct-

$\star \star * *$

TYpe A gaccctacagggctgaggacgctgtagcctaccetgtaggagtgccetgaagtgcgacgtgcaacaaaaccagatttgcccacgtgaccagcgacggcga Type B gaccctacagggctgaggacgctgtagcctaccetgtaggagtgccetgaagtgcgacgtgcaacaaaccagatttgcccacgtgaccagcgacggcga

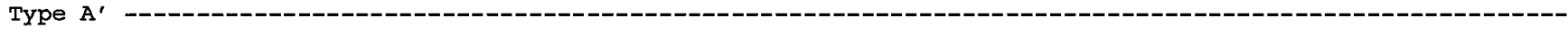

Type A gatcgctgggggaggetccaggctgctccgacaggcttctacacactgtagggacacctagaagtccettggcacctcccctacagcgtcggaggccetg Type B gatcgctgggggaggctccaggctgctccgacaggcttctacacactgta-

Type $A^{\prime}$

TYpe A tagccggccctgaaggagtgccctgaggtgcgacgtgcaacaaaaccagatctgcccacgtgattccctcagggtaggtcgagtgtggaattggtgggag

Type B

Type $A^{\prime}$

cagggtaggtcgagtgtggaattggtgggag

Type A aggctccaggctactcttacaggctatogtacactgtagacataccctagaagtcccttggcacctatcctacagcgtcggaggccetgtagctggccct

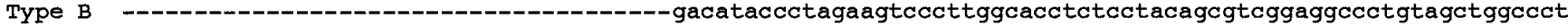
Type $A^{\prime}$ aggctccaggctactcttacaggctctcgtacactgtagacataccctagaagtccettggcacctctcctacagcgtcggaggccetgtagctggccct

Type A gaaggaatgccctgaactgcgacgtgcaacaaactoggaacgccaaggcctttggagggtaacccaagtgtgacccgtagccactccacctcacceaac Type B gaaggaatgccctgaactgcgacgtgcaacaaaactcggaacgccaaggcctttggagggtaacccaagtgtgacccgtagccactccacctcacccaac

Type $A^{\prime}$ gaaggaatgccctgaactgcgacgtgcaacaaaactcggaacgccaaggcctttggagggtaacccaagtgtgacccgtagccactccacctcacccaac

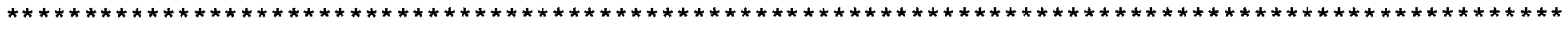

Type A tccccaaaccagggcogatcaggacctccogtatggtttctagagccattttttacgctgaatccgatggtgccattgactgctctatcaggggctgct Type B tcccccaaaccagggccgatcaggacctcccgtatggtttctagagccattttttacgctgaatccgatggtgccatt gactgctctatcaggggctgct Type $\mathrm{A}^{\prime}$ tcccccaaccagggccgatcaggacctcccgtatggtttctagagccattttttacgctgaatccgatggtgccattgactgctctatcaggggctgct

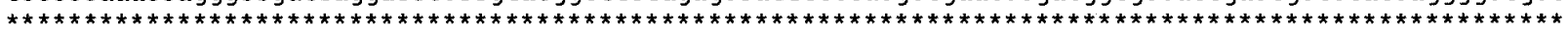

Type A aatgtggagtttaccccccccttgaggtataaagtgtcaagtatcaccgccaaggtggccgaatcggagccagccagccttttcatcgtgttgcccgcgg Type B aatgtggagtttaccccccccttgaggtataaagtgtcaagtatcaccgccaaggtggecgaatcggagccagccagccttttcatcgtgttgcccgegg Type $A^{\prime}$ aatgtggagtttacccccccttgaggtataaagtgtcaagtatcacc gccaaggtggccgaatcggagccagccagccttttcatcgtgttgcccgcgg

Type A ttgattacccatttaccactc

Type $B$ ttgattaccccatttaccactc

Type $A^{\prime}$ ttgattaccccatttaccactc

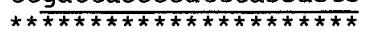

B

Type A' ggggttccgggattcacagggtagctcagatgtgagactggtgggagaggcttcagggcaccgctacaggcttctacacactgtaaggacacc-tagaag Type C ggggttccgggattcacagggtagctcagatgtgagactggtgggagaggcttcagggcaccgctacaggcttgtacacgctgtagacagaccctagcag

Type $A^{\prime}$ tccettggcacctccctacagcgtcggaggccetgtagccgaccetgaaggagtgcectgaggtgcgacgtgcaacaaaaccagatctgcccacgtgat

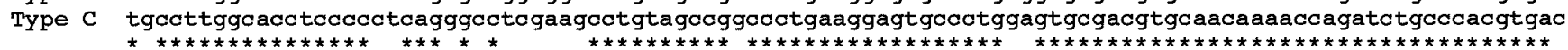

Type $A^{\prime}$ tccctcagggtaggtcgagtgtggaattggtgggagaggctccaggctactcttacaggctctcgtacactgtagacataccctagaagtcccttggcac Type C tctcccagggtaggtcgagtgtggaagtggtgggagaggcttcagggcaccgctacaggcttgtacacgctgtagacagaccctagcagtgccttggcac

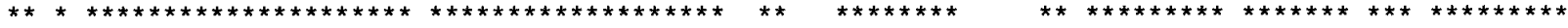

Type $A^{\prime}$ ctctcctacagcgtcggaggccetgtagctggccctgaaggaatgccctgaactgcgacgtgcaacaaaactcggaacgccaaggcctttggagggtaac Type C ctccccetcagggcetcgaagcctgtagccggccetgtaggagtgccetggagtgcgacgtgcaacaaaactcagaccgccaaggttttcggagggtaac

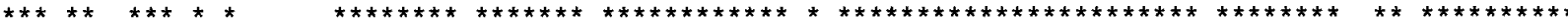

Type $A^{\prime}$ ccaagtgtgacccgtagccactccacctcacccaactcccccaaaccagggcogatcaggacctcccgtatggtttctagagccattttttacgctgaat Type C ccaagtgtgacccgcagccactccacctcacccaactcccccaaaccagggccgatcaggacctcccgtatggtttctagagccattttttacgctgaat

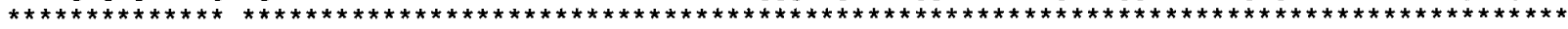

TYpe $A^{\prime}$ ccgatggtgccattgactgctctatcaggggctgctaatgtggagtttacccccccttgaggtataaagtgtcaagtatcacc gccaaggtggccgaat Type C ccgatggtgctattgactgctctatcaggggctgctaatgtggactttacccccacttgaggtataaagtgtcaagtatcactgccaagatggccgaat

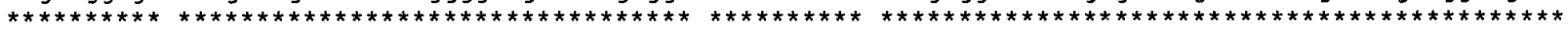

Type $A^{\prime}$ cggagccagccagcettttcatcgtgttgccegcggttgattaccccatttaccactc

Type C cggagccagccagcctttccatcgtgttgccegcggttgattaccccatttaccactc

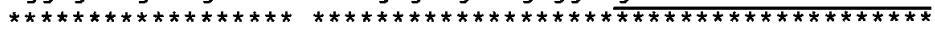

Fig. 6. Alignment of the sequences of polymerase chain reaction products amplified using specific primers BSRIGS1 and BSRIGS2 from Phialophora gregata. A, Genotypes A (AF249311), B (AF249312) and A' (AF249313) show identical sequences except the insertion of deletion. B, Genotypes A' and C (AF249314) show 58 nucleotide differences. An asterisk indicates that the column is a constant, and a - indicates an insertion or deletion. Primer sequences are underlined. 
Primer design and specificity. The two specific PCR primers flanking the variable region were tested for their specificity in $P$. gregata, a range of other fungal DNAs, and soybean DNA. Three distinct products of $1,020,830$, and $660 \mathrm{bp}$, were detected in isolates of $P$. gregata (Fig. 3). These bands were designated as genotypes A (1,020 bp), B (830 bp), and C (660 bp). No PCR products were detected when DNAs of the other fungi and soybean plant were used in PCR with the specific primers (gels not shown). In BLAST searches using the amplified sequences as queries, only four sequences of human and Drosophila from GenBank showed 20-bp stretches of similarity (search results not shown), suggesting that the sequences of this region are unique to P. gregata.

Genotyping of strains. Isolates of $P$. gregata were easily assigned to respective genotypes based on the PCR product sizes amplified with the specific primers, as shown in Figure 4. All 292 isolates from soybean and 8 isolates from mung bean belonged to either genotype A or B (Table 1), except two soybean isolates (WI2 and AS-1; described below). Genotype B also included the isolate ATCC 11073, the type culture of P. gregata (14) from the American Type Culture Collection (Manassas, VA). The two genotype $\mathrm{C}$ isolates were from Adzuki bean from Japan. Of the eight restriction enzymes used in digestion, enzymes RsaI and $X b a \mathrm{I}$ did not have restriction sites in the amplified region. Based on digestion with the other six enzymes, genotypes A and B always showed different restriction banding patterns, but no variation within each genotype was detected among isolates representing a wide geographic area (Fig. 5). Sequences of genotypes A and $\mathrm{B}$ in the amplified region were identical except for an 188-bp insertion or deletion at a discrete location (Fig. 6A).

Two isolates, WI2 and AS-1, showed the genotype A band but also showed a lower band similar in size to the genotype $\mathrm{C}$ band. The purity of these two isolates was confirmed by reisolating six single-spore subcultures. Each of the subcultures produced the same two bands. The two bands from each of the two isolates were purified after separation by agarose gel electrophoresis. Restriction enzyme digestion showed that the upper band had the same restriction banding pattern as the genotype A band from other soybean isolates, whereas the lower band had a completely different restriction banding pattern from that of the genotype $\mathrm{C}$ band from the two Adzuki bean isolates (digestion gels not shown). The lower band was then completely sequenced. Its sequence is identical to the genotype A band except two (one single base and one 365 base) insertion of deletion (Fig. 6A), and it differed from the genotype $\mathrm{C}$ band from the Adzuki bean in point mutations at 58 locations (Fig. 6B). Because the lower band in isolates WI2 and AS-1 was a derived form of, and always occured with, the genotype A band and appeared in low frequency ( 2 of 300 isolates), these two isolates were designated as genotype $\mathrm{A}^{\prime}$ and were tentatively considered genotype $\mathrm{A}$ in general discussions here. The four sequences of genotypes A, B, A', and C were deposited in GenBank and assigned Accession nos. AF249311, AF249312, AF249313, and AF249314, respectively.

Both genotype A and B isolates were found in the seven Midwestern states that we sampled, indicating that the two genotypes are widespread (Table 1). Genotype B was not detected in Brazil and Canada from a limited sample size of isolates. When the isolates were grouped based on cultivars or breeding lines from which the isolates were obtained, interesting trends in cultivar preference were observed (Table 2). For example, there were 17 isolates from the cv. Sturdy, 13 of them are of genotype A. Similarly, 34 of the 38 isolates from Pioneer 9305 are also genotype A. On the other hand, there were 23 isolates from $\mathrm{cv}$. SS282N, 17 of them were of genotype B. Seven of the nine isolates from cv. Bell were of genotype B. All 12 isolates from cv. IA 3003 were of genotype B. Interestingly, both cvs. Sturdy and Pioneer 9305 were susceptible to BSR, whereas the cvs. Bell, IA 3003 , and SS282N were resistant to BSR (27, Grau, unpublished

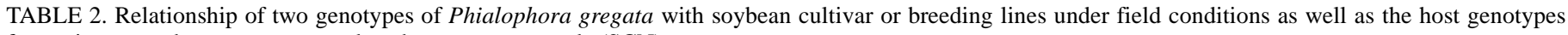
for resistance to brown stem rot and soybean cyst nematode (SCN)

\begin{tabular}{|c|c|c|c|c|c|}
\hline \multirow{2}{*}{$\begin{array}{l}\text { Cultivar/ } \\
\text { breeding lines }^{\mathrm{a}}\end{array}$} & \multirow{2}{*}{$\begin{array}{l}\text { Proposed } \\
R b s \text { gene }\end{array}$} & \multirow{2}{*}{$\begin{array}{c}\text { SCN resistance } \\
\text { source }\end{array}$} & \multicolumn{3}{|c|}{ Number of isolates of Phialophora gregata } \\
\hline & & & Genotype A & Genotype B & Total \\
\hline Archer & $R b s 1$ and $R b s 3$ & None & 4 & 0 & 4 \\
\hline A2247 & Resistant $^{\mathrm{b}}$ & None & 4 & 0 & 4 \\
\hline Bell & Resistant $^{\mathrm{b}}$ & PI 88788 & 2 & 7 & 9 \\
\hline BSR 101 & $R b s 1 \& R b s 3$ & None & 29 & 8 & 37 \\
\hline Century 84 & $r b s$ & None & 3 & 5 & 8 \\
\hline Corsoy & $r b s$ & None & 1 & 0 & 1 \\
\hline CX313 & $r b s$ & None & 4 & 1 & 5 \\
\hline H 1128 & $r b s$ & None & 2 & 0 & 2 \\
\hline Hardin & $r b s$ & None & 0 & 1 & 1 \\
\hline IA 3003 & Resistant $^{\mathrm{b}}$ & None & 0 & 12 & 12 \\
\hline KB 241 & $r b s$ & None & 4 & 0 & 4 \\
\hline L78-4094 & Rbs 1 & None & 1 & 0 & 1 \\
\hline LN92-12033 & $R b s 2$ & None & 2 & 21 & 23 \\
\hline LN92-12054 & $r b s$ & None & 3 & 15 & 18 \\
\hline Newton & $r b s$ & Peking & 5 & 0 & 5 \\
\hline S $19-90$ & $r b s$ & None & 0 & 1 & 1 \\
\hline PI 437833 & $R b s 2$ & None & 0 & 3 & 3 \\
\hline PI 437970 & Rbs 3 & None & 1 & 6 & 7 \\
\hline 9305 & $r b s$ & None & 34 & 4 & 38 \\
\hline SS24-92 & $r b s$ & None & 4 & 2 & 6 \\
\hline SS282N & Resistant $^{\mathrm{b}}$ & PI 88788 & 6 & 17 & 23 \\
\hline Sturdy & $r b s$ & None & $13^{c}$ & 4 & 17 \\
\hline Unknown & $\mathrm{N}^{\mathrm{d}} \mathrm{d}^{\mathrm{d}}$ & N/A & $49^{c}$ & 14 & 63 \\
\hline Total & & & 171 & 121 & $292^{\mathrm{e}}$ \\
\hline
\end{tabular}

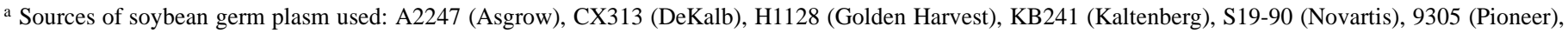
SS24-92 (Seiben), and SS282N (Seiben). All other germ plasm is from public sources.

b Cultivar expressed low levels of symptom severity of brown stem rot but without known Rbs genes.

c Includes one genotype A' isolate.

d Not applicable.

e Two isolates from Adzuki bean from Japan and eight isolates from mung bean were not included. 
data). Similar trends were also observed in the susceptible cv. Newton (five of five isolates were of genotype A), and resistant PI 437970 (six of seven isolates were of genotype B). Most of the isolates, 21 of 23 , and 15 of 18 , obtained from the $R b s 2$ nearisogenic lines (33), LN92-12033 (resistant), and LN92-12054 (susceptible), respectively, belonged to genotype B (Table 2). However, not all resistant cultivars were preferentially infected by genotype B. For example, 29 of 37 isolates from resistant cv. BSR101 were genotype A (Table 2).

Genotype detection in infected soybean plants. The purpose of this experiment was to verify that preferential infection by the genotypes occurred in cultivars growing in the same field. The specific primers were used successfully to detect the pathogen genotypes in infected soybean plants. Among 50 randomly collected (infected as well as noninfected) plants, 33 of them were positive for $P$. gregata based on the presence of a PCR product using the specific primers (Table 3). Cultivar preference by the two genotypes of $P$. gregata was also observed. For example, 11 plants of resistant cv. Bell were infected by $P$. gregata and 10 of them were infected by genotype B, whereas among 9 infected plants of the susceptible cultivar Sturdy, 7 of them were infected by genotype A. A similar trend was also seen in the susceptible cv. AP1991 (Table 3). Cultivar-preferential infection was significant in cvs. AP1991 and Bell and Sturdy (Table 3), but no significant difference was detected in cv. BSR 101. Two plants (one each in cvs. AP1991 and BSR 101) showed two PCR bands, a major band of genotype A and a minor band of genotype B (Table 3), probably the result of infection by both genotypes.

\section{DISCUSSION}

It is significant that soybean isolates of $P$. gregata can be separated into two subspecific populations (genotypes A and B) based on variation in the IGS region of the nuclear rDNA. It is the first experiment to show a genetic subdivision in soybean isolates of $P$. gregata. Furthermore, the two genotypes preferentially infect certain soybean cultivars under field conditions. Gray (16) reported two pathogenicity types of $P$. gregata on soybean, defoliating (type I) and nondefoliating (type II) (described in introduction). The original nondefoliating (type II) strain, ATCC 11073, the type culture on which the description of $P$. gregata was based (14), belonged to genotype B. A recent claim by Harrington et al. (20) that Plectosphaerella cucumerina and Gliocladium roseum were the non-defoliating (type II) form is contrary to the fact in the original report (16). Unfortunately, the strains of the original defoliating (type I) form were no longer available for genotyping in this study. In Japan, Kondo et al. (25) reported two races of $P$. gregata f. sp. adzukicola on Adzuki bean. It seems that the two forma speciales (adzukicola and sojae) of $P$. gregata have evolved in parallel on their respective hosts. The relationship of the two genotypes of soybean isolates with pathogenicity under controlled conditions remains to be assessed.

TABLE 3. Polymerase chain reaction detection of genotypes of Phialophora gregata in infected soybean plants of four cultivars growing in the same field near Arlington, WI

\begin{tabular}{lccccl}
\hline & & \multicolumn{4}{c}{ Number of plants harboring P. gregata } \\
\cline { 3 - 6 } Cultivar & $\begin{array}{c}\text { Number of } \\
\text { plants tested }\end{array}$ & Genotype A & Genotype B & Total & $\chi^{2 \mathrm{a}}$ \\
\hline AP1991 & 12 & $7^{\mathrm{b}}$ & 1 & 8 & $4.5^{* *}$ \\
Bell & 16 & 1 & 10 & 11 & $7.36^{* * *}$ \\
BSR101 & 10 & $2^{\mathrm{b}}$ & 3 & 5 & 0.2 \\
Sturdy & 12 & 7 & 2 & 9 & $2.78^{*}$ \\
Total & 50 & 17 & 16 & 33 & \\
\hline
\end{tabular}

a $*, * *$, and $* * *$ indicate significance at $\mathrm{P}<0.1,0.5$, and 0.01 , respectively.

$\mathrm{b}$ Includes one plant showing a faint genotype $\mathrm{B}$ band in addition to a major genotype A band.
In general, most isolates obtained from BSR-susceptible cultivars are of genotype A, and most isolates from resistant cultivars are of genotype B (Table 4). The susceptible cultivars could be arbitrarily subdivided into two groups. Susceptible group I was mostly infected by genotype A isolates, whereas susceptible group II, which includes Century 84 and LN92-12054, a near-isogenic line of BSR-resistant $R b s 2$ (33), was mostly infected by genotype B (Table 4). Resistant cultivars could be divided based on their resistance genes. BSR 101-derived resistant cultivars were mostly infected by genotype A, whereas all other resistant cultivars, including those with alleles $R b s$ 1, 2, and 3 breeding lines, were infected predominately by genotype B (Table 4). Genotype B also preferentially infected cvs. Bell and SS282N, both of which are resistant to both BSR and the soybean cyst nematode $(27$; C. R. Grau, unpublished data) with derived resistance from PI 88788 , whereas genotype A infected cv. Newton, which is resistant only to the soybean cyst nematode with derived resistance from Peking (Table 4). It appears that genotype B is adapted to some yet unidentified traits associated with certain resistant soybean cultivars.

The plants used in isolations of $P$. gregata were from different fields and different geographic locations (Table 1). The comparison of cultivar preference (Tables 2 and 4 ) is confounded by the fact that the distribution and relative abundance of the two genotypes in those fields are not known. However, the soybean cultivars used for DNA isolation and direct genotype detection were from the same field, and cultivar-preferential infection by the two genotypes is also evident (Table 3). Preferential infection of cvs. Bell and Sturdy by genotypes A and B, respectively, observed under the same field conditions (Table 3) is consistent with the data based on genotyping of isolates obtained from the same two cultivars (Table 2). This fact provides credence for concluding cultivar preference of the two genotypes based on genotyping of the isolates.

We previously showed that the ITS region of the rDNA contains no variation among soybean isolates of $P$. gregata and was used to separate $P$. gregata from other fungi, including Plectosporium tabacinum, that are ecologically associated with BSR $(10,12)$. Variation in the ITS region and an intron in the small subunit rDNA differentiate soybean isolates of $P$. gregata from Adzuki bean isolates $(10,11)$. Here we report that genetic variation in the IGS region can subdivide soybean isolates into two distinct populations (genotypes A and B), in addition to separating Adzuki bean isolates from soybean isolates. These studies demonstrate that the various regions of the rDNA evolve at different rates and

TABLE 4. Relationship between brown stem rot (BSR) disease reactions of soybean genotype groups and genotypes of Phialophora gregata

\begin{tabular}{lcc}
\hline & \multicolumn{2}{c}{ Number of isolates of P. gregata $^{2}$} \\
\cline { 2 - 3 } Soybean reaction group & Genotype A & Genotype B \\
\hline All BSR susceptible & 73 & 33 \\
Susceptible group I $^{\mathrm{a}}$ & 67 & 13 \\
Susceptible group II $^{\mathrm{b}}$ & 6 & 20 \\
All BSR resistant & 49 & 74 \\
BSR 101-derived resistance $^{\mathrm{c}}$ & 37 & 8 \\
Other resistance sources $^{\mathrm{d}}$ & 12 & 66 \\
$\quad$ Rbs 1, 2, and 3 breeding lines & 4 & 30 \\
SCN resistance, PI 88788 $^{\mathrm{f}}$ & 8 & 24 \\
SCN resistance, Peking $^{\mathrm{g}}$ & 5 & 0
\end{tabular}

${ }^{a}$ Includes Corsoy, DeKalb CX313, GH 1128, Hardin, KB241, Newton, NK19-90, Pioneer 9305, Seiben SS24-92, and Sturdy.

${ }^{\mathrm{b}}$ Includes Century 84 and LN92-12054 (a near isogenic line of Rbs 2).

${ }^{c}$ Includes Archer, ASGR A2247, and BSR 101.

d Includes Bell, IA 3003, L78-4094, LN92-12033, PI 437-833, PI 437-970, and Seiben SS282N.

e Includes L78-4094, LN92-12033, PI 437-833, and PI 437-970.

${ }^{\mathrm{f}}$ Soybean cyst nematode $(\mathrm{SCN})$ resistance derived from PI 88788 includes Bell and Seiben SS282N.

$\mathrm{g}$ Soybean cyst nematode resistance derived from Peking includes Newton. 
provide different levels of resolution for addressing specific questions at appropriate taxonomic levels.

The IGS region of $P$. gregata is unusually large $(\approx 7 \mathrm{~kb})$ compared with other fungi $(6,21,32,38,39)$, making it difficult to amplify the whole region. In basidomycetes and some morel fungi, 5S rDNA repeat units reside in the IGS region, and primers based on the conserved sequences in the large subunit rDNA and the 5S rDNA were used amplify a portion of the IGS region. The IGS region is approximately 2 to $2.5 \mathrm{~kb}$ in Verticillium spp. $(32,38)$ and approximately $2.6 \mathrm{~kb}$ in Fusarium oxysporum (6). In the studies of Verticillium and Fusarium spp. $(6,38)$, the restriction banding patterns of PCR-amplified IGS regions were used. However, the IGS region of $P$. gregata is too long for routine amplification. We sequenced the IGS region and designed specific primers flanking the variable location for easy PCR amplification and identification the genotypes.

Repeated-gene families like rDNA genes including spacer regions are subject to concerted evolution $(8,49)$, which means variation in the rDNA family is homogenized among the repeating units within an individual and among members of a population. The two distinct genotypes of the IGS region suggest that there are at least two separate evolving populations within soybean isolates of $P$. gregata. The IGS region of nuclear rDNA is unlikely to have a function in the infection process. The correlation of the genotypes with cultivar preference provides an example of nonrandom association of genetic traits. Furthermore, we have identified six additional DNA loci generated by microsatelliteprimered PCR that are strictly correlated with the two genotypes (X. Q. Meng and W. Chen, unpublished data), providing evidence that the genetic difference between genotypes A and B extends far beyond the rDNA and that there is limited gene flow between the two genotypes of $P$. gregata.

\section{ACKNOWLEDGMENTS}

We dedicate this publication to L. E. Gray of USDA-ARS for his many contributions to the understanding of, and insightful discussions about, brown stem rot, his encouraging and facilitating cooperative research efforts, and his enthusiastic support of this research. We thank A. Dorrance and X. B. Yang for providing $P$. gregata isolates for this study, and B. Diers for providing infected soybean plants used in isolation and for reviewing the manuscript. We thank Y.-C. Chen for technical assistance. This research was funded, in part, by grants from the CSREES North Central IPM Program, the Illinois Soybean Program Operating Board, the Illinois Council on Food and Agricultural Research (C-FAR), and the Wisconsin Soybean Marketing Board.

\section{LITERATURE CITED}

1. Adee, E. A., Grau, C. R., and Oplinger, E. S. 1995. Inoculum density of Phialophora gregata related to severity of brown stem rot and yield of soybean in microplot studies. Plant Dis. 79:68-73.

2. Adee, E. A., Grau, C. R., and Oplinger, E. S. 1997. Population dynamics of Phialophora gregata in soybean residue. Plant Dis. 81: 199-203.

3. Allington, W. B., and Chamberlain, D. W. 1948. Brown stem rot of soybean. Phytopathology 38:793-802.

4. Altschul, S. F., Gish, W., Miller, W., Myers, E. W., and Lipman, D. J. 1990. Basic local alignment search tool. J. Mol. Biol. 215:403-410.

5. Anderson, J. B., Bailey, S. S., and Pukkila, P. J. 1989. Variation in ribosomal DNA among biological species of Armillaria, a genus of rootinfecting fungi. Evol. 43:1652-1662.

6. Appel, D. J., and Gordon, T. R. 1995. Intraspecific variation within populations of Fusarium oxysporum based on RFLP analysis of the intergenic spacer region of the rDNA. Exp. Mycol. 19:120-128.

7. Appels, R., and Honeycutt, R. L. 1986. rDNA: Evolution over a billion years. Pages 81-135 in: DNA Systematics, Vol. 2. S. K. Dutta, ed. CRC Press, Boca Raton, FL.

8. Arnheim, N., Krystal, M., Schmickel, R., Wilson, G., Ryder, O., and Zimmer, E. 1980. Molecular evidence for genetic exchanges among ribosomal genes on nonhomologous chromosomes in man and apes.
Proc. Natl. Acad. Sci. USA 77:7323-7327.

9. Bachman, M. S., and Nickell, C. D. 1999. Use of reciprocal grafting to study brown stem rot resistance in soybean. Phytopathology 89:59-63.

10. Chen, W., Gray, L. E., and Grau, C. R. 1996. Molecular differentiation of fungi associated with brown stem rot and detection of Phialophora gregata in resistant and susceptible soybean cultivars. Phytopathology 86:1140-1148

11. Chen, W., Gray, L. E., and Grau, C. R. 1998. Characterization of a group I intron in nuclear rDNA differentiating Phialophora gregata f. sp. adzukicola from P. gregata f. sp. sojae. Mycoscience 39:279-283.

12. Chen, W., Gray, L. E., Kurle, J. E., and Grau, C. R. 1999. Specific detection of Phialophora gregata and Plectosporium tabacinum in infected soybean plants. Mol. Ecol. 8:871-877.

13. Chen, W., Hoy, J. W., and Schneider, R. W. 1992. Species-specific polymorphisms in transcribed ribosomal DNA of five Pythium species. Exp. Mycol. 16:22-34.

14. Gams, W. 1971. Cephalosporium-artige Schimmelpilze (Hyphomycetes). Gustav Fischer Verlag, Stuttgart, Germany.

15. Gourmet, C., Gray, L. E., and Rayburn, A. L. 1997. Flow citometric analysis of conidia of fungi isolated from soybean vascular tissue. J. Phytopathol. 145:405-408.

16. Gray, L. E. 1971. Variation in pathogenicity of Cephalosporium gregatum isolates. Phytopathology 61:1410-1411.

17. Gray, L. E. 1989. Brown stem rot. Pages 29-30 in: Compendium of Soybean Diseases. J. B. Sinclair and P. A. Backman, eds. The American Phytopathological Society, St. Paul, MN.

18. Gray, L. E., and Hepburn, A. G. 1992. Mitochondrial DNA restriction patterns of Phialophora gregata isolates from soybean and adzuki bean. Phytopathology 82:211-215.

19. Harikrishnan, R., and Yang, X. B. 1999. Development of soybean brown stem rot in relation to infested residue size, density and depth of placement. Can. J. Plant Sci. 79:469-472.

20. Harrington, T. C., Steimel, J., Workneh, F., and Yang, X. B. 2000. Molecular identification of fungi associated with vascular discoloration of soybean in the north central United States. Plant Dis. 84:83-89.

21. Henrion, B., Chevalier, G., and Martin, F. 1994. Typing truffle species by PCR amplification of the ribosomal DNA spacers. Mycol. Res. 98:37-43.

22. Hidebrand, A. A. 1948. An occurrence of brown stem rot of soybeans in Ontario. Sci. Agric. 23:261-263.

23. Jackson, C. J., Barton, R. C., and Evans, E. G. V. 1999. Species identification and strain differentiation of dematophyte fungi by analysis of ribosomal DNA intergenic spacer regions. J. Clinc. Microb. 37:931-936.

24. Kobayashi, K., Yamamoto, H., Negishi, H., and Ogoshi, A. 1991. Formae specialis differentiation of Phialophora gregata from adzuki bean and soybean in Japan. Ann. Phytopathol. Soc. Jpn 57:225-231.

25. Kondo, N., Fujita, S., Murata, K., and Ogoshi, A. 1998. Detection of two races of Phialophora gregata f. sp. adzukicola, the causal agent of adzuki bean brown stem rot. Plant Dis. 82:928-930.

26. Lewers, K. S., Crane, E. H., Bronson, C. R., Schupp, J. M., Keim, P., and Shoemaker, R. C. 1999. Detection of linked QTL for soybean brown stem rot resistance in 'BSR 101' as expressed in a growth chamber environment. Mole. Breeding 5:33-42.

27. MacGuidwin, A. E., Grau, C. R., and Oplinger, E. S. 1995. Impact of planting 'Bell', a soybean cultivar resistant to Heterodera glycines, in Wisconsin. J. Nematol. 27:78-85.

28. Mengistu, A., and Grau, C. R. 1986. Variation in morphological, cultural, and pathological characteristics of Phialophora gregata and Acremonium sp. recovered from soybean in Wisconsin. Plant Dis. 70:1005-1009.

29. Mengistu, A., and Grau, C. R. 1987. Seasonal progress of brown stem rot and its impact on soybean productivity. Phytopathology 77:15211529 .

30. Mengistu, A., Tachibana, H., and Grau, C. R. 1991. Selective medium for isolation and enumeration of Phialophora gregata from soybean straw and soil. Plant Dis. 75:196-199.

31. Morgan, F., and Dunleavy, J. M. 1966. Brown stem rot of soybeans in Mexico. Plant Dis. Rep. 50:598-599.

32. Morton, A., Tabrett, A. M., Carder, J. H., and Barbara, D. J. 1995. Subrepeat sequences in the ribosomal RNA intergenic regions of Verticillium alboatrum and V. dahliae. Mycol. Res. 99:257-266.

33. Nickell, C. D., Bachman, M. S., Stephens, P. A., Nickell, A. D., Cary, T. R., and Thomas, D. J. 1997. Registration of LN92-12033 and LN9212054 soybean germplasm lines near-isogenic for brown stem rot resistance gene Rbs2. Crop Sci. 37:1987.

34. Radford, S. A., Johnson, E. M., Leeming, J. P., Millar, M. R., Cornish, J. M., Foot, A. B., and Warnock, D. W. 1998. Molecular epidemiological study of Aspergillus fumigatus in a bone marrow transplantation unit by PCR amplification of ribosomal intergenic spacer sequences. J. Clin. Microbiol. 36:1294-1299. 
35. Sambrook, J., Fritsch, E. F., and Maniatis, T. 1989. Molecular Cloning:A Laboratory Manual. 2nd ed. Cold Spring Harbor Laboratory Press, Cold Spring Harbor, NY.

36. Sills, G. R., Gritton, E. T., and Grau, C. R. 1991. Differential reactions of soybean genotypes to isolates of Phialophora gregata. Plant Dis. 75:687-690.

37. Sinclair, J. B., and Backman, P. A. 1989. Compendium of Soybean diseases. The American Phytopathological Society, St. Paul, MN.

38. Subbarao, K. V., Chassot, A., Gordon, T. R., Hubbard, J. C., Bonello, P., Mullin, R., Okamoto, D., Davis, R. M., and Koike, S. T. 1995. Genetic relationships and cross pathogenicity of Verticillium dahliae isolates from cauliflower and other crops. Phytopathology 85:1105-1112.

39. Tan, M. K., Wong, P. T. W., and Holley, M. P. 1994. Characterization of nuclear ribosomal DNA (rDNA) in Gaeumannomyces graminis and correlation of rDNA variation with $G$. graminis varieties. Mycol. Res. 98:553-561.

40. Thompson, J. D., Higgins, D. G., and Gibson, T. J. 1994. Clustal W: Improving the sensitivity of progressive multiple sequence alignment though sequence weighting, position-specific gap penalties and weight matrix choice. Nucleic Acids Res. 22:4673-4680.

41. Tosic, M., and Bustrov, D. 1986. Phialophora gregata, the cause of brown stem rot of soybean, present in Yugoslavia. Zastita Bilja 37:59-66.

42. Vilgalys, R., and Hester, M. 1990. Rapid genetic identification and mapping of enzymatically amplified ribosomal DNA from several
Cryptococcus species. J. Bacterial. 172:4238-4246.

43. White, T. J., Bruns, T., Lee, S., and Taylor, J. 1990. Amplification and direct sequencing of fungal ribosomal RNA genes for phylogenetics. Pages 315-322 in: PCR Protocols: A Guide to Methods and Applications. M. A. Innis, D. H. Gelfand, J. J. Sninsky, and T. J. White, eds. Academic Press, San Diego, CA.

44. Willmot, D. B., and Nickell, C. D. 1989. Genetic analysis of brown stem rot resistance in soybean. Crop Sci. 29:672-674.

45. Willmot, D. B., Nickell, C. D., and Gray, L. E. 1989. Physiologic specialization of Phialophora gregata on soybean. Plant Dis. 73:290294.

46. Workneh, F., Tylka, G. L., Yang, X. B., Faghihi, J., and Ferris, J. M. 1999. Regional assessment of soybean brown stem rot, Phytophthora sojae, and Heterodera glycines using area-frame sampling: Prevalence and effects of tillage. Phytopathology 89:204-211.

47. Yamamoto, H., Kobayashi, K., and Ogoshi, A. 1990. Isozyme polymorphism in Phialophora gregata isolates from adzuki bean and soybean in Japan. Ann. Phytopathol. Soc. Jpn. 56:584-590.

48. Yamamoto, H., Kobayashi, K., and Ogoshi, A. 1995. Characterization of the nuclear DNA of Phialophora gregata f. sp. adzukicola and sojae. Mycoscience 36:117-119.

49. Zimmer, E. A., Martin, S. L., Beverlry, S. M., Kan, Y. W., and Wilson, A. C. 1980. Rapid duplication and loss of genes coding for the $\alpha$-chains of hemoglobin. Proc. Natl. Acad. Sci. USA 77:2158-2162. 